\title{
Prevalence of Enterobius vermicularis infections and associated risk factors among schoolchildren in Nakhon $\mathrm{Si}$ Thammarat, Thailand
}

Pokkamol Laoraksawong ${ }^{1}$, Pimyada Pansuwan ${ }^{2}$, Supakrit Krongchon ${ }^{2}$. Pongphan Pongpanitanont ${ }^{2}$ and Penchom Janwan ${ }^{2 *}$

\begin{abstract}
Background: Enterobius vermicularis infection is an important public health problem worldwide, especially among schoolchildren in tropical and subtropical countries. The prevalence of E. vermicularis infections varies in each region of Thailand; however, its status remains unknown among children who live in rural areas of the southern region. This study aimed to evaluate the current prevalence of E. vermicularis infections and to identify the risk factors for infection among schoolchildren who live in rural communities in Nakhon Si Thammarat, Southern Thailand.

Results: The overall prevalence of E. vermicularis infections was 5.79\% (23 of 397). According to a multivariate analysis, the following were found to be risk factors associated with $E$. vermicularis infections $(P<0.05)$ : those of the male sex ( $A O R=4.03,95 \% \mathrm{Cl} 1.22-13.29)$, those in the 3-6year age group ( $A O R=4.85,95 \% \mathrm{Cl} 1.51-15.59)$, those who have a mother with a primary school education level $(A O R=11.22,95 \% \mathrm{Cl} 1.75-71.77)$, those who have older sibling(s) (AOR $=6.25,95 \% \mathrm{Cl} 1.83-21.26)$, those who have younger sibling(s) (AOR $=6.24,95 \% \mathrm{Cl} 2.00-19.44)$, those who sometimes wash their hands after using the toilet ( $A O R=5.25,95 \% \mathrm{Cl} 1.24-22.21$ ), those who keep their fingernails long ( $A O R=29.97,95 \% \mathrm{Cl} 6.16-145.85)$, and those who suck their fingers ( $\mathrm{AOR}=3.59,95 \% \mathrm{Cl} 1.21-10.66)$.

Conclusions: This was the first report that revealed the prevalence of $E$. vermicularis infections among children who live in rural areas of Southern Thailand through detection using the Scotch tape technique. This study demonstrated that the high prevalence of $E$. vermicularis infections in schoolchildren with siblings was a significant independent predictor and that the transmission of this infection may occur in the family through their school-age siblings. In addition, children who have poor personal hygiene have a high prevalence of $E$. vermicularis infections. Therefore, maintaining good handwashing habits, keeping one's fingernails short, and avoiding sucking one's fingers should be important preventive measures against infection. Moreover, health literacy or health education, especially for parents or the principal caretakers of children, should be implemented to reduce E. vermicularis infections.
\end{abstract}

Keywords: Enterobius vermicularis, Prevalence, Risk factors, Schoolchildren, Southern Thailand

\footnotetext{
* Correspondence: penchom.ja@wu.ac.th

${ }^{2}$ Department of Medical Technology, School of Allied Health Sciences,

Walailak University, Nakhon Si Thammarat, Thailand

Full list of author information is available at the end of the article
}

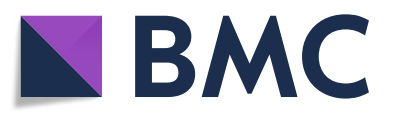

(- The Author(s). 2020 Open Access This article is licensed under a Creative Commons Attribution 4.0 International License, which permits use, sharing, adaptation, distribution and reproduction in any medium or format, as long as you give appropriate credit to the original author(s) and the source, provide a link to the Creative Commons licence, and indicate if changes were made. The images or other third party material in this article are included in the article's Creative Commons licence, unless indicated otherwise in a credit line to the material. If material is not included in the article's Creative Commons licence and your intended use is not permitted by statutory regulation or exceeds the permitted use, you will need to obtain permission directly from the copyright holder. To view a copy of this licence, visit http://creativecommons.org/licenses/by/4.0/ 


\section{Background}

Enterobiasis is an intestinal nematode infection caused by Enterobius vermicularis, commonly known as pinworms. E. vermicularis infection is an important public health problem among schoolchildren, especially in tropical and subtropical countries [1,2], with an estimate of over 1 billion infections [3]. Most of the infections are asymptomatic. Common enterobiasis symptoms include itching, irritation of the perianal region, and vaginal pruritus in females $[4,5]$. In severe infection cases, the symptoms include insomnia, weight loss, vomiting, abdominal pain, and appendicitis $[2,6,7]$. E. vermicularis has a simple life cycle, where it is transmitted via the finger-oral route, inhalation, or reinfection $[1,6,8]$.

In many parts of the world, the prevalence of E. vermicularis infections varies between 0.21 and $54.86 \%$ [1-3, 8-17]. In Thailand, the prevalence of E. vermicularis infections varies between 0 and $50.90 \%$ [18-30]. Schoolchildren who live in crowded environments and have poor personal hygiene are the most commonly infected group [10, 22]. Although various studies have been conducted on the distribution and prevalence of $E$. vermicularis infections in Thailand, epidemiological information on E. vermicularis infections is lacking for several remote regions, especially Southern Thailand. A national survey of helminthiasis in Thailand that was conducted in 2009 showed a prevalence rate of $0.2 \%$ for E. vermicularis infections in Southern Thailand [31]. A survey of intestinal parasitic infections in Nakhon Si Thammarat, Southern Thailand, that was conducted in 2016 showed a $0.3 \%$ prevalence rate for E. vermicularis infections [32]. However, these recent publications found E. vermicularis infections incidentally through methods of parasitological surveys that did not employ the Scotch tape technique, which is the gold standard for $E$. vermicularis detection. Consequently, this study aimed to evaluate the prevalence of $E$. vermicularis infections among schoolchildren in the Tha Sala District of Nakhon Si Thammarat using the Scotch tape technique and to identify the potential risk factors for infection in the study area. The results are important for monitoring and implementing effective control strategies, as well as for providing supplemental data to convince policymakers that this infection remains important.

\section{Methods}

\section{Study design and area}

A cross-sectional study was conducted from June to July 2019 and included schoolchildren living in rural areas of the Taling Chan and Sa Kaeo subdistricts of the Tha Sala District, Nakhon Si Thammarat Province, Southern Thailand. The study area is approximately located 754 $\mathrm{km}$ south of Bangkok, the capital city of Thailand. The average temperature is $27.3^{\circ} \mathrm{C}$, with a low of $23.7{ }^{\circ} \mathrm{C}$ and a high of $35.2^{\circ} \mathrm{C}$. The annual rainfall is $2150.0 \mathrm{~mm}$ [33].
The Taling Chan and Sa Kaeo subdistricts cover an area of 60.63 and $39.50 \mathrm{~km}^{2}$, respectively, with geographical locations at 8.770288 latitude and 99.885376 longitude, and 8.762168 latitude and 99.914407 longitude, respectively (Fig. 1). Both the Taling Chan and Sa Kaeo subdistricts are similar in terms of topography, climate, natural resources, land use, culture, and economic status.

\section{Study population, sample size, and sampling technique}

Schoolchildren from 3 to 9 years of age who agreed to participate and whose parents or legal guardians gave consent were included. The sample size was determined using the finite single population proportion formula as follows [34]:

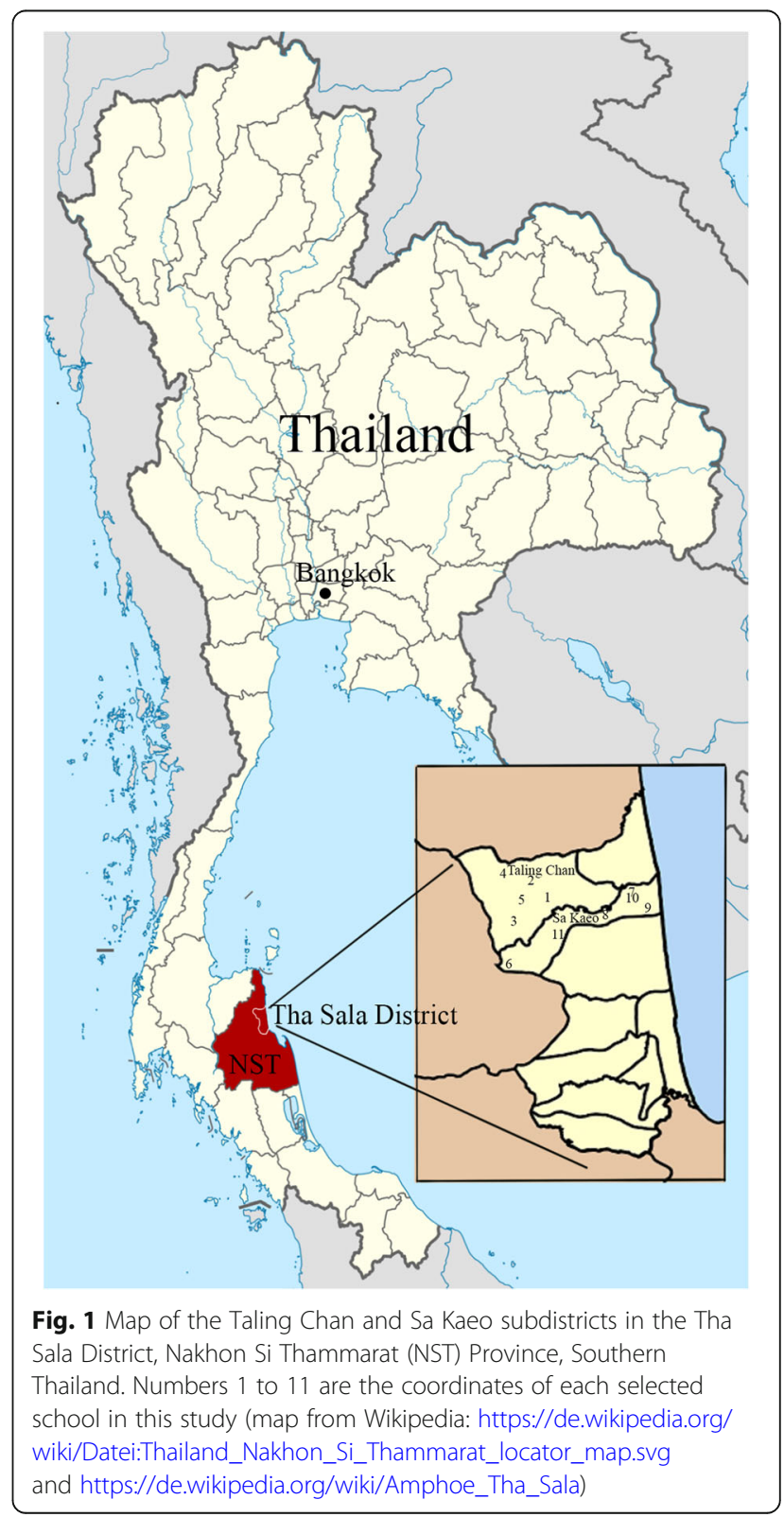




$$
n=\frac{N p(1-p) Z_{1-\alpha / 2}^{2}}{d^{2}(N-1)+p(1-p) Z_{1-\alpha / 2}^{2}}
$$

The sample size was calculated using a prevalence rate $(p)$ of $39.0 \%$, as detailed in a previous study [20], with a $95 \%$ confidence interval $(95 \% \mathrm{CI})(z=1.96)$ and a $5 \%$ margin of error $(d=0.05)$. The population of the students from 3 to 9 years of age in Tha Sala District totaled 5412 persons [35]. The calculated sample size was 343 people. The final sample size was 378 individuals, including a $10 \%$ nonresponse rate among the students. The participants were randomly selected from all 11 kindergarten and primary schools within the Taling Chan and Sa Kaeo subdistricts using a voluntary sampling method.

\section{Parasitological survey and data collection}

Letters of information, informed consent forms, and self-administered questionnaires were given to parents or legal guardians prior to pinworm screening. Parents and children were informed about the timing of the experiment in advance. The collection of samples was performed in the morning before the defecating and bathing of the children. Children were diagnosed for $E$. vermicularis infections based on the Scotch tape technique [6]. Only one sample was taken from each child, and the microscopic examinations were performed by two medical technologists. The child's parents or principal caretakers were asked to complete a questionnaire that inquired about the potential risk factors involved. The questionnaire (Additional file 1) was developed and used to access data such as information related to demographics, personal hygiene, and household sanitary conditions. We collected information on the child's gender, the child's age, the number of household members, the presence of older/younger sibling(s), the parents' education level, the parents' occupation, the parents' income, handwashing behavior, fingernail trimming, finger sucking, playing with others, bathing behavior, underwear washing, towel or bed-sharing, anthelmintic medication, living conditions, and household cleaning.

\section{Data analysis}

The total data were cleaned, entered, and analyzed using STATA version 10.1 (STATA Corp., TX, USA). The demographic characteristics of the participants were described using frequencies, percentages, and 95\% CI for categorical data; means and standard deviations (SD) were used for continuous data. To investigate factors that affected $E$. vermicularis infections, the prevalence rate, $95 \% \mathrm{CI}$, and odds ratios (ORs) were estimated using simple and multiple logistic regressions and a generalized estimating equation (GEE). To adjust for possible confounders, all variables with a $P$ value less than 0.2 in the univariate analysis were selected. A $P$ value of less than 0.05 was considered statistically significant.

\section{Results}

Demographic characteristics

From a total of 859 schoolchildren (aged 3-9 years in 2 subdistricts) included in the study, 397 and their parents responded, making the response rate $46.2 \%$. In total, 397 children were enrolled in this study; 205 (51.64\%) of the children were girls and $192(48.36 \%)$ were boys. The mean $( \pm$ SD) age of the children was $6.79( \pm 1.74)$ years (Additional file 2: Table S1).

\section{Personal hygiene behaviors}

Two hundred and forty-nine $(62.72 \%)$ of the children reported sometimes washing their hands after using toilet facilities. Three hundred and eighty-one (95.97\%) of children reported keeping their fingernails short, and 332 $(83.63 \%)$ of the children reported not sucking their fingers (Additional file 3: Table S2). Univariate analyses of personal hygienic factors indicated that there were no significant associations between pinworm infection and washing ones' hands before eating, taking a bath before sleeping or after waking up, bathing without the help of family members, or washing one's underwear without the help of family members $(P>0.05)$ (Additional file 3 : Table S2). However, a significant higher risk of pinworm infection was found in the children who reported sometimes washing their hands after using toilet facilities, keeping their fingernails long, sucking their fingers, and sharing towels with others $(P<0.05)$ (Additional file 3: Table S2).

\section{Household sanitary conditions}

Three hundred and eighty-eight (97.73\%) children reported living in a single-family detached home. One hundred and fifty-nine (40.05\%) families reported changing their bedding once every 2 weeks, and three hundred and twenty-five (81.86\%) reported always cleaning their house (Additional file 4: Table S3). Univariate analyses of household sanitary conditions indicated that there were no significant associations between pinworm infection and the style of residence, the home structure, the type of bed, and the frequency of changing the bedding or cleaning the house $(P>0.05)$ (Additional file 4: Table S3).

\section{Prevalence of $E$. vermicularis infections}

The overall prevalence of $E$. vermicularis infections through detection using the Scotch tape technique was $5.79 \%$ (95\% CI 3.48-8.10). This prevalence rate of infection was higher in boys $(7.29 \%)$ than in girls (4.39\%). The egg-positive rate ranged from 0 to $15.79 \%$ (95\% CI 
$0.99-1.01, P=0.72$ ) by location. No significant differences in egg-positive rates according to school were observed (Table 1).

\section{Factors associated with $E$. vermicularis infections}

According to the multivariate analysis, gender, age group, mother's education level, having older sibling(s), having younger sibling(s), washing one's hands after using toilet facilities, keeping one's fingernails short, and sucking one's fingers were found to be risk factors associated with $E$. vermicularis infections $(P<0.05)$. Boys were 4.03 times more likely (AOR $=4.03,95 \%$ CI $1.22-$ 13.29) to be infected than girls. Meanwhile, children 3 to 6 years of age were 4.85 times more likely $(\mathrm{AOR}=4.85$, 95\% CI 1.51-15.59) to be infected than children 7 to 9 years of age. Children who had a mother with primary school education level were 11.22 times more at risk $(\mathrm{AOR}=11.22,95 \% \mathrm{CI} 1.75-71.77)$ to be infected than those who had a mother with a higher level of education. Moreover, children who had older sibling(s) were 6.25 times more likely (AOR $=6.25,95 \%$ CI $1.83-21.26)$ to be infected than children who did not have older siblings. Additionally, children who had younger sibling(s) were 6.24 times $(\mathrm{AOR}=6.24,95 \%$ CI $2.00-19.44$ ) more likely to be infected than children who did not have younger sibling(s). Furthermore, children who did not frequently wash their hands after using toilet facilities were 5.25 times more likely ( $\mathrm{AOR}=5.25$, 95\% CI 1.2422.21) to be infected than those who did wash their hands. Children who kept their fingernails long were 29.97 times more likely (AOR $=29.97,95 \%$ CI 6.16-145.85) to be infected than those who kept them short. Additionally, children who sucked their fingers were 3.59 times more likely $(\mathrm{AOR}=3.59,95 \%$ CI $1.21-10.66)$ to be infected than those who did not suck them (Table 2).

Table 1 Prevalence of Enterobius vermicularis infection among the study participants from the 11 kindergarten and primary schools

\begin{tabular}{llll}
\hline School & Number examination & Number positive & Positive (\%) \\
\hline 1 & 58 & 2 & 3.45 \\
2 & 32 & 0 & 0 \\
3 & 19 & 3 & 15.79 \\
4 & 29 & 1 & 3.45 \\
5 & 46 & 5 & 10.87 \\
6 & 37 & 4 & 10.81 \\
7 & 42 & 3 & 7.14 \\
8 & 41 & 1 & 2.44 \\
9 & 19 & 0 & 0 \\
10 & 43 & 1 & 2.32 \\
11 & 31 & 3 & 9.68 \\
\hline
\end{tabular}

\section{Discussion}

This is the first report that reveals the prevalence of $E$. vermicularis infections among children who live in rural areas of Southern Thailand through detection using the Scotch tape technique. In this study, the overall prevalence of E. vermicularis infections was 5.79\%, lower than the values found in previous studies that have been conducted in other regions of Thailand. This discrepancy may partly be due to the study setting and the source population difference. The prevalence of pinworm infections ranges from 7.81 to $38.82 \%$ [19-21, 27, 28, 30], 11.30 to $50.90 \%$ [18, 29], and 7.25 to $45.38 \%$ [22-25] in the central, northeast, and northern regions of Thailand, respectively. However, according to these studies, the prevalence of $E$. vermicularis infections in Thailand tends to be lower over the past three decades mainly due to sanitary environments and healthcare access being greatly improved by urbanization.

Our study revealed that boys are more highly infected with $E$. vermicularis than girls, which was also observed in previous studies $[9,12]$. Higher infection rates among boys may be due to boys being involved in more activities, being in closer contact with other children, and having poorer personal hygiene than girls. Among the age groups, children 3 to 6 years of age are more at risk to be infected with $E$. vermicularis, which is consistent with the findings of previous studies $[13,29,30]$. This could be because this age group engages in more group activities together, such as taking naps together during the day on floor mats, and because they have poorer personal hygiene than older children.

The three main factors that are often involved in $E$. vermicularis infections among children are family background, living conditions, and personal hygiene. In the present study, children with mothers who have a primary school level of education have a higher risk of infection. This finding is similar to those reported previously $[1,13]$, and it may be explained by the fact that mothers with low education levels may not have accurate knowledge of pinworm infection even though they are the principal caretaker of their children. Meanwhile, previous reports have suggested that parents' knowledge about enterobiasis might be one of the most important risk factors for enterobiasis in children [11, 14]. In addition, children who have younger/older siblings are more highly infected with $E$. vermicularis than those who do not, and these findings are similar to those reported previously $[1,12,17]$. These results suggest that new infection or reinfection may occur in the family among children who are in constant close contact over long periods of time. Further, it seems that residents, including parents or caretakers, should also be investigated and treated. The medications used for the treatment of pinworm are either albendazole, mebendazole, or pyrantel 
Table 2 Multivariate analysis of risk factors associated with Enterobius vermicularis infections among the study participants

\begin{tabular}{|c|c|c|c|c|c|}
\hline Characteristics & Total number & Number positive $\left(\mathrm{PR}^{\mathrm{a}}\right)$ & $\mathrm{COR}^{\mathrm{b}}$ & $\operatorname{AOR}^{c}\left(95 \% \mathrm{Cl}^{d}\right)$ & $P$ value \\
\hline \multicolumn{6}{|l|}{ Gender } \\
\hline Female & 205 & $9(4.4)$ & 1 & 1 & \multirow[t]{2}{*}{$0.022^{*}$} \\
\hline Male & 192 & $14(7.3)$ & 1.7 & $4.03(1.2-13.3)$ & \\
\hline \multicolumn{6}{|l|}{ Age group } \\
\hline 7 to 9 years & 242 & $10(4.1)$ & 1 & 1 & \multirow[t]{2}{*}{$0.008^{*}$} \\
\hline 3 to 6 years & 155 & $13(8.4)$ & 2.1 & $4.85(1.5-15.6)$ & \\
\hline \multicolumn{6}{|l|}{ Mother's education level } \\
\hline Diploma, bachelor's, or higher & 56 & $2(3.6)$ & 1 & 1 & \multirow[t]{3}{*}{$0.016^{*}$} \\
\hline Secondary school & 215 & $13(6.1)$ & 1.7 & $4.11(0.7-22.6)$ & \\
\hline Primary school & 126 & $8(6.4)$ & 1.8 & $11.22(1.8-71.8)$ & \\
\hline \multicolumn{6}{|l|}{ Have older sibling(s) } \\
\hline No & 184 & $5(2.7)$ & 1 & 1 & \multirow[t]{2}{*}{$0.003^{*}$} \\
\hline Yes & 213 & $18(8.5)$ & 3.3 & $6.25(1.8-21.3)$ & \\
\hline \multicolumn{6}{|l|}{ Have younger sibling(s) } \\
\hline No & 270 & $11(4.1)$ & 1 & 1 & \multirow[t]{2}{*}{$0.002^{*}$} \\
\hline Yes & 127 & $12(9.5)$ & 2.5 & $6.24(2.0-19.4)$ & \\
\hline \multicolumn{6}{|c|}{ Wash hands after using toilet facilities } \\
\hline Always & 148 & $3(2.0)$ & 1 & 1 & \multirow[t]{2}{*}{$0.024^{*}$} \\
\hline Sometimes & 249 & $20(8.0)$ & 4.2 & $5.25(1.2-22.2)$ & \\
\hline \multicolumn{6}{|l|}{ Keep fingernails short } \\
\hline Yes & 381 & $16(4.2)$ & 1 & 1 & \multirow[t]{2}{*}{$<0.001^{*}$} \\
\hline No & 16 & $7(43.8)$ & 17.7 & $29.97(6.2-145.9)$ & \\
\hline \multicolumn{6}{|l|}{ Sucks fingers } \\
\hline No & 332 & $12(3.6)$ & 1 & 1 & \multirow[t]{2}{*}{$0.022^{*}$} \\
\hline Yes & 65 & $11(16.9)$ & 5.4 & $3.59(1.2-10.7)$ & \\
\hline
\end{tabular}

*Significant association

${ }^{a} P R$ prevalence rate in each group

${ }^{\mathrm{b}} \mathrm{COR}$ crude odds ratio by univariable analysis

${ }^{\mathrm{C}} A O R$ adjusted odds ratio by multivariable analysis

${ }^{d} \mathrm{Cl}$ 95\% confidence interval

pamoate. Single doses of albendazole (400 mg), mebendazole $(100 \mathrm{mg})$, or pyrantel pamoate $(11 \mathrm{mg} / \mathrm{kg}$ up to $1 \mathrm{~g})$ are highly effective. A second dose is given 2 weeks later because of the frequency of reinfection and autoinfection. Repeated infections should be treated using the same method as that used during the first infection. In households where more than one member is infected or where infections are repeated, symptomatic infections occur; thus, it is recommended that all household members be treated at the same time. In institutions, a mass simultaneous treatment that is repeated in 2 weeks can be effective $[4,6,36]$. The eggs are very lightweight and can thus be distributed into the surrounding environment. Dust-borne infection; indirect infection through clothing, bedding, or food; or direct infection by hand from the anus to the mouth is possible, particularly for children in rural areas with inadequate personal hygiene, especially those who engage in fingernail sucking or biting and do not frequently wash their hands. Prophylaxis is dependent primarily on personal hygiene behaviors and household sanitary conditions $[4,6]$.

Previous reports have suggested that inadequate personal hygiene can increase the risk of enterobiasis in children [1,11, 13-15]. Our study shows that children who do not frequently wash their hands after using toilet facilities are more at risk to be infected with pinworms. This finding is similar to those reported previously $[1,14]$, indicating that direct infection by hand from the anus to the mouth might occur. Additionally, it also causes distribution into the surrounding environment. Moreover, children who suck their fingers are more at risk to be infected with E. vermicularis, which is consistent with the findings of other studies $[11,15]$. Interestingly, we found that children who keep their fingernails long are more at risk to be infected with pinworms, which is consistent with the 
findings of a previous study [11]. This could be due to pinworm eggs that may be transferred from contaminated hands to one's mouth. Finally, in our study, these findings indicate that the finger-oral route remains the most important avenue for E. vermicularis transmission.

One limitation in our study was related to using a single-day Scotch tape technique for parasite examination, which is not valid enough to measure the true prevalence of pinworm infection. The prevalence demonstrated in this study was underestimated. Another important limitation was that the causes and risk factors associated with $E$. vermicularis infection might not be strongly demonstrated from the cross-sectional design of the study.

\section{Conclusion}

This current study demonstrated that having siblings as a schoolchild is a significant independent predictor of the high prevalence of E. vermicularis infections and that the transmission of this infection may occur in the family through school-age siblings. In addition, children who have poor personal hygiene have a high prevalence of $E$. vermicularis infections. Therefore, good handwashing habits, keeping one's fingernails short, and avoiding sucking fingers should be important preventive measures against the infection. Moreover, health literacy or health education, especially for parents or the principal caretakers of children, should be implemented to reduce $E$. vermicularis infections. Additionally, these results should encourage policymakers and public health personnel to improve programs for pinworm control and health promotion.

\section{Supplementary information}

Supplementary information accompanies this paper at https://doi.org/10. 1186/s41182-020-00270-3.

Additional file 1. Questionnaire for demographic, personal hygiene, and household sanitary conditions data collection.

Additional file 2: Table S1. Univariate analysis of the demographic characteristics of the study participants.

Additional file 3: Table S2. Univariate analysis of personal hygiene factors associated with Enterobius vermicularis infections among the study participants.

Additional file 4: Table S3. Univariate analysis of household sanitary conditions associated with Enterobius vermicularis infections among the study participants.

\section{Abbreviations}

Cl: Confidence interval; SD: Standard deviation; THB: Thai baht; OR: Odds ratio; COR: Crude odds ratio; AOR: Adjusted odds ratio

\section{Acknowledgements}

We would like to thank all of the participants, including the schoolchildren, the parents or legal guardians of children, and the teachers, for their cooperation and support throughout this study. Acknowledgements also go to the Center for Scientific and Technological Equipment, Walailak University, for the laboratory instruments and research area. We would also like to thank Mr. David C. Chang for the English language and editing support via the Publication Clinic, Walailak University, Thailand.

\section{Authors' contributions}

PJ and PL conceived and designed the study. SK, PPO, PJ, and PP performed the experiments. PL and PJ performed the statistical analysis, interpreted the data, and wrote the first draft. All the authors have approved the final version of the manuscript and its conclusions.

\section{Funding}

This study was supported by a grant from the Association of Medical Technologist of Thailand (AMTT) under the Royal Patronage of HRH Princess Soamsawali 2019, partially supported by the New Strategic Research (P2P) project (phase 2), Walailak University, Thailand, and a Distinguished Research Professor Grant, Thailand Research Fund (grant number DPG6280002). The funding authority does not have roles in this study.

\section{Availability of data and materials}

All data generated or analyzed during this study are included in this published article and its supplementary information files. The raw data are available from the corresponding author on reasonable request.

\section{Ethics approval and consent to participate}

Ethical approval was obtained from the Ethics Committee on Human Rights Related to Research Involving Human Subjects, Walailak University (Protocol No. WUEC-19-095-01). All research was performed in accordance with the Declaration of Helsinki. The aim and all processes of the study were fully described to the children and parents or legal guardians, and participation was voluntary. Written informed consent was obtained from a parent or guardian on behalf of any participants under the age of 16 before data and sample collection. Confidentiality and anonymity of the information has remained.

\section{Consent for publication}

Not applicable.

\section{Competing interests}

We declare that we do not have any competing interests.

\section{Author details}

${ }^{1}$ School of Health Science, Sukhothai Thammathirat Open University, Nonthaburi, Thailand. ${ }^{2}$ Department of Medical Technology, School of Allied Health Sciences, Walailak University, Nakhon Si Thammarat, Thailand.

Received: 28 June 2020 Accepted: 20 September 2020

Published online: 29 September 2020

\section{References}

1. Chen $K Y$, Yen CM, Hwang KP, Wang LC. Enterobius vermicularis infection and its risk factors among pre-school children in Taipei, Taiwan. J Microbiol Immunol Infect. 2018;51(4):559-64.

2. Dudlova A, Juris P, Jarcuska P, Vasilkova Z, Vargova V, Sumkova M, et al. The incidence of pinworm (Enterobius vermicularis) in pre-school and school aged children in the eastern Slovakia. Helminthologia. 2018;55(4):275-80.

3. Lohiya GS, Tan-Figueroa L, Crinella FM, Lohiya S. Epidemiology and control of enterobiasis in a developmental center. West J Med. 2000;172(5):305-8.

4. Cook GC. Enterobius vermicularis infection. Gut. 1994;35:1159-62.

5. Burkhart CN, Burkhart CG. Assessment of frequency, transmission, and genitourinary complications of enterobiasis (pinworms). Int I Dermatol. 2005:44(10):837-40,

6. Shoup B. Diagnosis and management of pinworm infection. Primary Care Update for OB/GYNS. 2001;8(6):240-3.

7. Hammood ZD, Salih AM, Mohammed SH, Kakamad FH, Salih KM, Omar DA, et al. Enterobius vermicularis causing acute appendicitis, a case report with literature review. Int J Surg Case Rep. 2019:63:153-6.

8. Pezzani BC, Minvielle MC, de Luca MM, Córdoba MA, Apezteguía MC, Basualdo JA. Enterobius vermicularis infection among population of General Mansilla, Argentina. World J Gastroenterol. 2004;10(17):2535-9. 
9. Park JH, Han ET, Kim WH, Shin EH, Guk SM, Kim JL, et al. A survey of Enterobius vermicularis infection among children on western and southern coastal islands of the Republic of Korea. Korean J Parasitol. 2005;43(4):129-34.

10. Chang TK, Liao CW, Huang YC, Chang CC, Chou CM, Tsay HC, et al. Prevalence of Enterobius vermicularis infection among preschool children in kindergartens of Taipei City, Taiwan in 2008. Korean J Parasitol. 2009;47(2): 185-7.

11. Kim DH, Son HM, Kim JY, Cho MK, Park MK, Kang SY, et al. Parents' knowledge about enterobiasis might be one of the most important risk factors for enterobiasis in children. Korean J Parasitol. 2010;48(2):121-6.

12. Gunawardena NK, Chandrasena TN, de Silva NR. Prevalence of enterobiasis among primary school children in Ragama, Sri Lanka. Ceylon Med J. 2013; 58(3):106-10.

13. Li HM, Zhou CH, Li ZS, Deng ZH, Ruan CW, Zhang QM, et al. Risk factors for Enterobius vermicularis infection in children in Gaozhou, Guangdong, China. Infect Dis Poverty. 2015;4:28.

14. Suraweera O, Galgamuwa LS, Iddawela D, Wickramasinghe S. Prevalence and associated factors of Enterobius vermicularis infection in children from a poor urban community in Sri Lanka: a cross-sectional study. Int J Res Med Sci. 2015;3(8):1994-9.

15. Wang S, Yao Z, Hou Y, Wang D, Zhang H, Ma J, et al. Prevalence of Enterobius vermicularis among preschool children in 2003 and 2013 in Xinxiang city, Henan province, Central China. Parasite. 2016;23:30.

16. Amiri SA, Rahimi MT, Mahdavi SA, Moosazadeh M, Ramzani O, Koshk AF, et al. Prevalence of Enterobius vermicularis infection among preschool children, Babol, North of Iran. J Parasit Dis. 2016;40(4):1558-62.

17. Fan CK, Chuang TW, Huang YC, Yin AW, Chou CM, Hsu YT, et al. Enterobius vermicularis infection: prevalence and risk factors among preschool children in kindergarten in the capital area, Republic of the Marshall Islands. BMC Infect Dis. 2019:19(1):536

18. Kaewkes S, Tesana S, Sithithaworn P, Srisawangwonk T, Raengsangounwong P. Enterobiasis in young school children in Bangkok. J Parasitol Trop Med Assoc Thai. 1983;6:19-24

19. Nithikathkul C, Changsap B, Wannapinyosheep S, Poister C, Boontan P. The prevalence of enterobiasis in children attending mobile health clinic of Huachiew Chalermprakiet University. Southeast Asian J Trop Med Public Health. 2001;32(Suppl 2):138-42.

20. Nithikathkul C, Changsap B, Wannapinyosheep S, Poister C, Boontan P. The prevalence of Enterobius vermicularis among primary school students in Samut Prakan Province, Thailand. Southeast Asian J Trop Med Public Health. 2001;32(Suppl 2):133-7.

21. Changsap B, Nithikathkul C, Boontan P, Wannapinyosheep S, Vongvanich N, Poister C. Enterobiasis in primary schools in Bang Khun Thian District, Bangkok, Thailand. Southeast Asian J Trop Med Public Health. 2002;33(Suppl 3):72-5.

22. Tukaew A, Chaisalee T, Nithiuthai S, Thiamtip S, Suyaphun A, Wiwanitkit V, et al. Enterobius vermicularis infection among pre-school children in Karen hilltribe villages in Chiang Mai, Thailand. Southeast Asian J Trop Med Public Health. 2002;33(Suppl 3):70-1.

23. Nithikathkul C, Polseela P, Poodendan W, Brodsky M, Rakprapapant D, Chadchatreechan S, et al. Malaria and enterobiasis among Karen Long-neck tribe in Mae Hong Son Province. Southeast Asian J Trop Med Public Health. 2003;34(Suppl 2):25-8

24. Saksirisampant W, Prownebon J, Kulkumthorn M, Yenthakam S, Janpla S, Nuchprayoon S. Prevalence of intestinal parasitic infections among school children in the central region of Thailand. J Med Assoc Thai. 2006;89(11): 1928-33.

25. Nateeworanart S, Vitta A, Lee UP. Egg positive rate of Enterobius vermicularis in children in a rural area of Phichit province, Thailand. Southeast Asian J Trop Med Public Health. 2007;38(Suppl 1):40-2.

26. Pethleart A, Saichua P, Rhongbutsri P, Leelawongtawon R, Aree K, Tiengtip $R$, et al. Prevalence and risk factors for pinworm infection in the kindergarten of Thammasat University, Thailand. Southeast Asian J Trop Med Public Health. 2010:41(2):306-10.

27. Kitvatanachai $S$, Rhongbutsri P. Pinworm infections in suburban government schools in Lak Hok subdistrict, Muang Pathum Thani, Thailand. Rangsit Journal of Arts and Sciences. 2014;4(2):117-22.

28. Sagnuankiat $\mathrm{S}$, Wanichsuwan $\mathrm{M}$, Bhunnachet $\mathrm{E}$, Jungarat $\mathrm{N}$, Panraksa $\mathrm{K}$, Komalamisra C, et al. Health status of immigrant children and environmental survey of child daycare centers in Samut Sakhon province, Thailand. J Immigr Minor Health. 2016;18(1):21-7.
29. Laoraksawong P, Pradidthaprecha A, Kaladee A. Prevalence of Enterobius vermicularis infection among students from elementary schools, Chaiyaphum Province, Thailand. J Sci Technol Mahasarakham Univ. 2018; 37(4):486-93.

30. Taylor A, Saichua P, Rhongbutsri P, Tiengtip R, Kitvatanachai S, Taylor WRJ. A preliminary epidemiological study of pinworm infection in Thaklong Municipal Early Childhood Development Center and Rangsit Babies' Home, Pathum Thani, Thailand. BMC Res Notes. 2018;11(1):603.

31. Wongsaroj T, Nithikathkul C, Rojkitikul W, Nakaia W, Royal L, Rammasut P. National survey of helminthiasis in Thailand. Asian Biomed. 2014;8(6):779-83.

32. Punsawad C, Phasuk N, Bunratsami S, Thongtup K, Viriyavejakul P, Palipoch $S$, et al. Prevalence of intestinal parasitic infections and associated risk factors for hookworm infections among primary schoolchildren in rural areas of Nakhon Si Thammarat, southern Thailand. BMC Public Health. 2018; 18(1):1118.

33. Office of Agricultural Economics. Climate and irrigation; agricultural statistics of Thailand. http://www.oae.go.th/assets/portals/1/files/jounal/2562/ yearbook2561.pdf. Published 2018. Accessed 10 Aug 2019.

34. Wayne WD. Biostatistics: a foundation of analysis in the health sciences. 6th ed. New York: Wiley; 1995.

35. Office of the Basic Education Commission. Education Management Information System. Basic School Information of Nakhon Si Thammarat 2019. https://data.bopp-obec.info/emis/school.php?Area_CODE=8004. Accessed 10 Feb 2019

36. CDC. Pinworm infection. https://www.cdc.gov/parasites/pinworm/treatment. html. Published 2016. Accessed 21 Aug 2020.

\section{Publisher's Note}

Springer Nature remains neutral with regard to jurisdictional claims in published maps and institutional affiliations.

Ready to submit your research? Choose BMC and benefit from:

- fast, convenient online submission

- thorough peer review by experienced researchers in your field

- rapid publication on acceptance

- support for research data, including large and complex data types

- gold Open Access which fosters wider collaboration and increased citations

- maximum visibility for your research: over $100 \mathrm{M}$ website views per year

At BMC, research is always in progress.

Learn more biomedcentral.com/submissions 